\title{
NEOLIBERALISMO, REFORMA DO ESTADO E O PÚBLICO-NÃO-ESTATAL: NOVOS CONTORNOS ENTRE O PÚBLICO E O PRIVADO
}

\author{
NEOLIBERALISM, STATE REFORM AND PUBLIC NON-STATE: THE NEW \\ BORDERS BETWEEN PUBLIC AND PRIVATE
}

Henrique André Ramos Wellen ${ }^{1}$

\section{RESUMO}

As Ciências Sociais são influenciadas, periodicamente, por um debate acerca das relações entre espaço público e espaço privado e suas implicações nos contornos do Estado. Nas últimas décadas, esse debate foi alimentado por dois elementos centrais: o recrudescimento da precariedade das políticas sociais e a negação das conquistas históricas dos trabalhadores, complementados por novas formas de intervenção social que servem, na sua essência, para transferir o papel e a responsabilidade do Estado para organizações e corporações privadas. Com base numa breve análise histórica sobre a implementação desses recursos, observa-se uma nova fratura no espaço público, expressa, inclusive, na sua especificidade de esfera subjetiva, pois transforma a capacidade de atendimento universal da política pública em assistência particular. Surge, assim, uma nova determinação no debate entre público e privado, que instala um abismo entre essas duas esferas sociais e que implica diretamente a organização dos atores coletivos.

Palavras-chave: Ciências Sociais. Público. Privado. Capitalismo. Reforma gerencial.

\footnotetext{
1 Doutor em Serviço Social - ESS / UFRJ e professor de Ciências Sociais e Ciência Política da UNIFAL, e-mail
} para contato: e-mail: harw@uol.com.br. 


\section{ABSTRACT}

Social Sciences are influenced, periodically, by a debate concerning the relations between public space and private space and its implications in the contours of the State. In the last few decades, this debate was fed by two central elements: the decline of the social politics and the negation of the historical conquests of the workers, complemented by new ways of social intervention that act, in its essence, in the transfer of the State role and responsibility to private organizations and corporations. Analyzing historically the implementation of these resources, a new breaking in the public space is observed, that is expressed, also, in the subjective sphere, because it transforms the capacity of universal attendance of the public politics into particular assistance. It appears, thus, a new determination in the debate between private and public, which installs an abyss between these two social spheres and it implies directly in the organization of the collective actors.

Key Words: Social Sciences. Public. Private. Capitalism. Management reform.

\section{INTRODUÇÃO}

As Ciências Sociais são influenciadas, periodicamente, por um debate acerca das relações entre espaço público e espaço privado e suas implicações nos contornos do Estado. Nas últimas décadas, esse debate foi alimentado por dois elementos ideológicos centrais: o recrudescimento da precariedade das políticas sociais e a negação das conquistas históricas dos trabaIhadores, complementados por novas formas de intervenção social que servem, na sua essência, para transferir o papel e a responsabilidade do Estado para organizações e corporações privadas.

Neste pequeno ensaio procurou-se resgatar brevemente esse processo em questão, demonstrando que o fator central (material e ideológico) merecedor de destaque é a transmutação da legalidade mercantil para o Estado, através das inserções de mecanismos que induzem a um "pensamento lucrativo" em detrimento de necessidades sociais (ou em termos técnicos, a supressão da efetividade pela eficiência). Nesse sentido, procurou-se demonstrar a vinculação desta proposta ao ideário capitalista neoliberal, apontando para a sua dupla funcionalidade na vigência deste sistema econômico e ideológico: pelo lado econômico e/ou material, ao propor regressões nos direitos e garantias sociais dos trabalhadores, e pelo lado cultural/ ideológico, disseminando práticas e discursos voltados para a desmobilização política e social.

Para tanto, procurou-se analisar as "propostas de eficiência" difundidas na Reforma Gerencial, implementada com a Reforma do Estado Brasileiro ocorrida na década de 90 a partir das intervenções do Ministério da Administração Federal e Reforma do Estado (MARE), sob tutela do Ministro Luiz Carlos Bresser Pereira², durante o governo de Fernando Henrique Cardoso.

\footnotetext{
2 Bresser Pereira, depois de ter implementado com sucesso a Reforma Gerencial no Estado brasileiro, se tornou Ministro da Ciência e Tecnologia. Afirma ele: "quando o Presidente Fernando Henrique Cardoso me convidou para ser seu Ministro da Ciência e Tecnologia, começou afirmando que entendia que o mais importante a ser feito no Ministério da Administração Federal e Reforma do Estado estava feito. Talvez ele tenha razão. A reforma institucional foi aprovada. Minha passagem pelo MARE foi a melhor experiência de governo que tive em minha vida. Nestes quatro anos pude formular um plano geral - o Plano Diretor da Reforma do Aparelho Estado - propondo a Reforma Gerencial da administração pública brasileira, e, baseado nos princípios ali definidos, ver aprovada quase na íntegra a respectiva emenda constitucional. Mais do que isto, vi as novas idéias serem adotadas pela opinião pública, e - o que é mais importante pela alta administração pública brasileira" (BRESSER PEREIRA, 1999, p. 01).
} 


\section{CRISE DO CAPITALISMO, REESTRUTURAÇÃO PRODUTIVA E ESTADO NEOLIBERAL}

Como forma de justificar a necessidade de implementação da Reforma Gerencial no Brasil, Bresser Pereira advoga a ideia que existe uma grande crise no Estado brasileiro que o impossibilita de permanecer com a manutenção de altos índices de gastos sociais, sendo necessária uma reformulação na sua estrutura e funcionamento. Além disso, para o autor, em tempos de globalização, com a integração mundial dos mercados, tornou-se imperativo ${ }^{3}$ repensar o papel dos Estados, deixando de lado qualidades historicamente superadas de intervenção social, para limitar-se ao seu novo papel: tornar a economia nacional competitiva internacionalmente. Vale salientar que, segundo ele, este quadro de crise havia sido desprezado e agravado pelos governantes anteriores, só se tornando "um tema central no Brasil em 1995, após a eleição e a posse de Fernando Henrique Cardoso" (BRESSER PEREIRA, 1997, p. 01).

Para o autor, a crise no Estado brasileiro, que acompanhou o itinerário mundial de crises nos Estados nacionais, que se tornaram inflados de gastos sociais, endividados e incapazes de suas funções, foi acarretada a partir de quatro problemas centrais: crise fiscal, caracterizada "pela perda do crédito público e por poupança pública negativa"; crise no modo de intervenção do Estado, caracterizada "pelo esgotamento do modelo protecionista de substituição de importações", que demonstrou a incapacidade da tentativa do Estado brasileiro de criar qualidades sociais referentes a um Estado de Bem-Estar Social; crise da administração estatal burocrática, agravada pela instauração da Constituição de 1988, que levou a um "enrijecimento burocrático extremo", tendo como consequências "o alto custo e a baixa qualidade da administração pública brasileira"; e uma crise política, que perpassou três momentos distintos: uma crise de legitimidade durante o regime militar, uma crise de adaptação ao regime democrático, derivada da "tentativa populista de voltar aos anos 50", e uma crise moral que "levou ao impeachment de Fernando Collor de Mello" (BRESSER PEREIRA, 1996, p. 03- 04).

Diferentemente do que advoga Bresser Pereira, a partir de uma análise histórica, observa-se que existiu uma crise no modo de produção capitalista, gerada por um quadro de superprodução, no qual a oferta se tornou exponencialmente superior à demanda, induzindo a níveis decrescentes de taxas de lucratividade e acumulação. Como é próprio da lógica do capital, para se alcançar maiores taxas de lucratividade, as empresas procuram melhorar a produtividade através de investimentos em novas formas de gestão e tecnologias, aumentando a quantidade de trabalho morto em relação ao trabalho vivo (aumento da composição orgânica do capital), o que acarreta num tempo maior de retorno do investimento (maior tempo de rotação do capital) e gera, ainda, com a inserção de novas tecnologias e ganhos de produtividade, a possibilidade de um processo de barateamento dos custos da produção através de demissão de mão-de-obra, uma vez que poderá se produzir mais com menos funcionários.

Com esse acréscimo na quantidade de produtos ofertados no mercado, assim como pela diminuição de consumidores demandados (gerando um poder de compra potencialmente inferior), chega-se ao momento em que uma parte considerável das mercadorias não vai ser vendida (produtos sobrando no mercado), acarretando na não realização da mais-valia e induzindo à queda na lucratividade e acumulação. Esse processo de crise do capitalismo, que já tinha se caracterizado mundialmente em períodos de recessão anteriores (1824 - 1847; 1874 - 1893; e

3 Termo que é usado costumeiramente: "A crise do Estado impôs a necessidade de reconstrui-lo; a globalização tornou imperativo redefinir suas funções" (BRESSER PEREIRA, 1996, p. 01); "No Brasil, a reforma do Estado começou nesse momento, em meio a uma grande crise econômica, que chega ao auge em 1990 com um episódio hiperinflacionário. A partir de então a reforma do Estado se torna imperiosa" (BRESSER PEREIRA, 1997, p. 01) (grifos nossos). 
1914 - 1939, essa última a mais conhecida, através da ressonância da crise de 1929, com a quebra da bolsa de Nova lorque)m veio à tona a partir de 1962 na França, sendo também ocasionada em outros países: Itália (1963), Japão (1964), Alemanha Ocidental (1966/67), Grã-Bretanha (1970/71), e em escala mundial a partir de 1974/75 (MANDEL, 1982).

Com a nova crise do capitalismo gerada pela superprodução, surgiram, como consequências, quedas nas taxas de acumulação e um profundo estado de recessão, apontando como forma de remediar a queda de recursos econômicos da burguesia a necessidade de uma reestruturação produtiva para aumentar as taxas de exploração em vistas de alcance dos superlucros. Neste sentido, como forma de sustentação política e ideológica desta proposta, a burguesia elegeu como mais eficiente a proposta neoliberal que estava sendo germinada desde o final da década de 40 e que, finalmente, teria sua chance de mostrar serviço. Para dar sequência e amplitude ao processo de reestruturação do capital, se fazia necessária a implementação de um sistema que desse vazão e legitimidade às novas regras, por isso "o neoliberalismo é uma superestrutura ideológica e política que acompanha uma transformação histórica do capitalismo moderno" (THERBORN, 1995, p. 39).

Em concomitância com a implementação de novas formas de produção, avançando em relação ao padrão fordista, gerou-se a produção flexível que teve como aspecto de maior importância o aumento da mais-valia, seja esta relativa ou absoluta. Com isso, no lugar da produção em massa (para atender a um consumo - limitado aos países desenvolvidos - também de massa, auxiliado pelos investimentos do Estado na elevação do poder de compra da população, gerando um incremento na massa monetária), engendrou-se o capitalismo flexível.

Todavia, este não era possível de se realizar sozinho, requerendo uma intervenção social para obstruir as organizações da classe trabalhadora que tensionavam para baixo a taxa de exploração e impediam a geração de montantes maiores de lucros. Visto que "toda crise implica a irremediável reestruturação da relação capitalista e, portanto, simultaneamente, de suas formas econômicas e políticas" (FIORI, 2003, p. 109), ou inda que, "as crises são, portanto, por excelência, o momento em que se repõem ou se refazem as relações entre formas políticas e econômica da dominação" (FIORI, 2003, p. 110), para reerguer o sistema capitalista era indispensável, além das alterações no modo de produção, mudanças no aparelho estatal. Surgiu, neste contexto, a fomentação de um Estado que conseguisse auxiliar no processo de renovação das forças da burguesia, gerando um processo dialético gradativo com duas diretrizes centrais. Para deixar o mercado livre seria preciso, de um lado, prover a garantia da estabilidade monetária e a privatização de organizações estatais; e, de outro, um combate às organizações da classe trabaIhadora.

Atrelando um discurso de elevada carga ideológica e uma proposta de maior exploração da força de trabalho, os precursores do neoliberalismo se desvirtuaram de uma análise histórica que, mais uma vez, demonstrou a validade da teoria marxista das crises econômicas, negando a realidade concreta e a inevitabilidade das crises do capital, colocando aqueles que foram as vítimas no lugar de réus. Escamotearam que a crise econômica fora gerada por processos de superprodução e caracterizaram como principais fatores da recessão econômica existente as pressões da classe trabalhadora sobre o Estado e as empresas.

A crise econômica e social do capitalismo, segundo o discurso mistificador dos neoliberais, tinha sua causa no excessivo poder de barganha das organizações da classe trabalhadora, que pressionavam tanto as empresas para obter maiores garantias de trabalho e menor exploração, gerando diminuição nas taxas de lucro e acumulação, quanto o Estado, a fim de assegurar direitos trabalhistas e sociais - o que acarretou no aumento dos gastos. A pressão por parte dos 
trabalhadores, ao implicar diretamente a redução das taxas de lucros empresariais, induziria, inclusive, ao aumento da inflação.

Segundo os representantes do ideário neoliberal, se este ciclo de limitação humana (ou, para estes ideólogos, de uma semi-escravidão ${ }^{4}$ ) prosseguisse, iria afetar seriamente a economia de mercado. Assim, como forma de remediar esse quadro seria preciso "manter um Estado forte, sim, em sua capacidade de romper o poder dos sindicatos e no controle do dinheiro, mas parco em todos os gastos sociais e nas intervenções econômicas" (ANDERSON, 2003, p. 11). Para assegurar a plena liberdade econômica e fazer com que as transações comerciais voltassem a fluir normalmente, seria preciso estabelecer como meta suprema a estabilidade monetária, que seria alcançada por meio de três diretrizes: disciplina orçamentária; contenção dos gastos sociais; e uma política de teor malthusiana de geração de desemprego, ampliando o exército industrial de reserva e, com isso, pondo em risco a existência dos sindicatos.

Para regredir ao suposto Estado liberal que outrora era preciso, além de um Estado não intervencionista na economia, foram limitadas suas responsabilidades, acarretando a adoção de uma política de privatizações e também em um Estado forte para combater a classe trabalhadora. Como o novo contexto se diferenciava do antigo pela organização dos sindicatos e dos trabalhadores, se fez importante um combate ao trabalho para voltar aos níveis de dominação do capital simétricos aos anteriores. Desta forma, se por um lado o Estado deveria prover um maior financiamento às empresas privadas, de outra forma precisava combater a classe trabalhadora, se tornando, portanto, um Estado máximo para o capital e mínimo para o trabalho (NETTO, 1993).

Em outras palavras, no novo contexto de recessão, surgido a partir da crise do capital e do capitalismo, agravada em horizonte mundial depois dos anos 70, observa-se que, em paralelo às necessidades impostas pelo capital para a adoção de uma reestruturação produtiva, por meio da qual se procuraram novas formas de organização e gestão do trabalho com vistas ao aumento das taxas de mais-valia, ocorreu também uma mudança na dimensão do próprio Estado capitalista. Se esse Estado, durante as décadas de 40 a 60, se colocou enquanto agente necessário para regulação e intervenção da economia, intentando assegurar uma estabilidade através da amenização de problemas sociais (o que induziu ao requisito de concessões de conquistas trabaIhistas), a partir do início dos anos 70, com a vigência de uma nova grande crise de superprodução, o Estado também foi tensionado pelo capital a se "reestruturar". Com a crise de superprodução e acumulação, a qual o Estado de Bem Estar Social não era capaz de solucionar, ainda mais porque já estava endividado devido ao financiamento da burguesia, era necessário um novo Estado, como funções diferentes do anterior. Dentre essas novas atribuições, destacava-se a sua gradativa retirada na intervenção econômica e social, mas não antes o combate à classe trabalhadora, através do aumento da desigualdade e de desemprego, intentando contra as organizações de tal classe.

Como forma de garantir a possibilidade de aumento dos lucros, o Estado passou, de um lado, a restringir sua atuação social, e de outro, a expandir o financiamento ao capital. Por isso, passou a ampliar as características de um Estado repressor do trabalho, estruturado centralmente no combate à organização sindical e outras conquistas trabalhistas, e de provedor de auxílios para o reerguimento do capital. É deste contexto que surgem as teorias sobre a escassez do Estado e da impossibilidade de o mercado se responsabilizar por custos sociais.

${ }^{4}$ Conforme defende Hayek na sua obra "O caminho da servidão". 
No momento que o Estado se retira do campo social para abrir espaço a formas mais ampliadas de exploração do trabalho, ele é posto como incapaz de solucionar ou amenizar problemas sociais; quando ele está endividado devido aos excessivos gastos sociais (conforme o discurso de Bresser Pereira), completa-se a versão ideológica de escassez e crise fiscal do Estado. Todavia, com esta defesa não se completa o percurso da problemática, ou seja, falta a posição do Estado em relação ao capital.

Se o Estado, para permitir e incentivar que os empresários consigam galgar dilatados montantes de lucros, pode, de formas variadas - desde a renúncia fiscal, passando pela diminuição dos impostos sobre grandes fortunas até o financiamento direto das grandes empresas -, conceder grande parte de seus recursos arrecadados, ele faz diminuir de forma considerável a sua receita disponível para investimentos. Além disso, como a lógica privatista se alastra por diversas áreas do Estado, incitando ao tratamento de importância secundária dos investimentos sociais (saúde, educação, seguridade social etc.) e privilegiando contratos de pagamentos das agências capitalistas internacionais, a capacidade de manutenção de políticas sociais de qualidade passa a ser minimizada.

Completando o ciclo, como o mercado, ou o capital, é situado como se "não tivesse nada a ver com isso" e como deve dar preferência à geração de lucro (inclusive ideologicamente vinculado à geração de emprego), o mercado também se torna um setor ausente dos problemas sociais, não sendo considerado como responsável pela sua resolução e nem tido como relacionado com a sua causa. No final, têm-se a visão de um Estado incapaz e de um mercado que não tem nada com isso. Dois setores atomizados e desvinculados da realidade: do Estado não se pode cobrar nada, uma vez que, devido à sua situação frágil, este não pode fazer nada além do que é corrente; e do mercado não se deve exigir nada, visto que as suas características peculiares econômicas determinam a limitação de seu escopo, de modo que este já faz o máximo possível e qualquer ajuda que exceda será entendida como um imenso favor ao povo. Com a visão desses dois setores separados pelas suas características conjunturais específicas, um apenas político e outro somente econômico, resta o principal: cuidar do social. Como se verá mais na frente, esta será a tarefa do novo setor, o público-não-estatal.

Entretanto, se o Estado Neoliberal, ao destruir as garantias e os direitos dos trabalhadores - conquistados após vários anos de luta -, gera uma conjuntura configurada a partir da constância de conflitos sociais, colocando em crise sua própria legitimidade, como seria possível que mantivesse sua existência?

Como a ofensiva neoliberal repercutiria, inevitavelmente, numa crise de legitimação, acarretada pelo aumento dos problemas sociais, seria preciso também uma dominação ideológica. Desta maneira, como forma de combater o trabalho, o Estado neoliberal atuaria em duas frentes: material (precarizando, desempregando e empobrecendo a classe trabalhadora) e ideológica (disseminando formas "alternativas" de pensamento que induzissem à apatia política, além de se auto-intitular como única solução possível para o futuro da humanidade).

Neste sentido, com o objetivo de criar uma visão de mundo que favoreça a sua legitimação, a proposta capitalista difundiu a premissa de que não existem alternativas a tal modelo, de maneira que "todos, seja confessando ou negando, têm de adaptar-se a suas normas" (ANDERSON, 2003, p. 23). Em última análise, esta ideologia busca proclamar "o triunfo final e definitivo do capitalismo", o fim da história ${ }^{5}$, ocultando, pois, a transitoriedade à qual, historicamente, os meios de produção estão condenados (BORÓN, 2003, p. 185).

\footnotetext{
${ }^{5}$ Expressão usada por Fukuyama, "[funcionário] do Departamento de Estado norte-americano que publicou um pequeno artigo na revista National Interest intitulado 'O fim da história?'. O artigo repercutiu tanto que, de 15 a 17 de maio de 1991, a Associação dos Amigos da Libraire Sauramps organizou um debate em Montpellier, destacando a discussão sobre este tema. Os anais foram publicados sob a coordenação de
} 
O neoliberalismo, desta forma, fixou-se como o senso comum de nossa época, dificultando a discussão de novas (ou velhas, mas não ultrapassadas) propostas, ridicularizando quem ousa discuti-las, calando vozes de senso crítico. Se na etapa histórica anterior, durante a primeira fase do capitalismo monopolista, do século XX, a estratégia de hegemonia "do capital aponta no sentido de diminuir as resistências operárias mediante a incorporação sistemática de demandas trabalhistas, mostrando um sistema (e um Estado) capaz de gerar 'bem-estar social' para todos", na fase atual do capitalismo, "a estratégia aposta na desmobilização mediante a resignação frente a fenômenos supostamente naturais, irreversíveis, inalteráveis" (MONTAÑO, 2002, p. 142).

Com o intento de alcançar a hegemonia da ideologia neoliberal, fez-se preciso providenciar um ataque "às bases da esperança que se construiu nos anos mais duros. O que não é uma coisa de menor importância [...] Metamorfoseia esse movimento de esperança num movimento derrotista" (OLIVEIRA, 2003, p. 27). Desta forma, esta proposta, própria de "qualquer doutrina classista hegemônica", pretende "que seu sistema produtivo se configure por categorias de validade atemporal ou de duração infinita, por determinações de leis naturais e racionais" (ROMÃO, 2000 , p. 143). Seria, portanto, o fim da história.

Vale salientar que esse processo afetou a economia mundial, mas de forma diferenciada entre os diversos países, de acordo com suas especificidades. Assim, para analisar o caso brasileiro, se faz indispensável levar em conta as mediações brasileiras que norteiam a nossa formação da economia, da sociedade e do Estado.

A formação do Estado brasileiro se deu de forma peculiar, uma vez que esteve sempre a serviço direto das classes dominantes, estabelecendo-se a partir de uma politização da economia ou acumulação politizada ${ }^{6}$. Nossa história é marcada por um pacto social, no qual o Estado brasileiro costumeiramente se colocou como unidade de possibilidades e limites das diferentes classes burguesas (agrícolas - oligárquicas; industriais - nacionais; multinacionais - estrangeiras; financeira), estabelecendo um desenvolvimento desigual, porém combinado, e mantendo, simultaneamente, na sua pauta de ações, uma decisão de investimento para assegurar o setor agrícola (inclusive estabelecido pela acumulação primitiva), o investimento na industrialização e, ainda, a remuneração a partir do pagamento de juros da dívida, do capital financeiro.

O Estado como esfera do pacto social, utilizando-se de formas autoritárias de dominação e repressão em momentos de conflitos sociais, também inviabilizou a construção de um sistema democrático em potencial, com ampla participação política e construção de partidos políticos de massa. Sendo o Estado mantenedor da política e da economia, a participação política e os parti-

Bernard Lefort em 1995. Impressionado com o próprio sucesso, Fukuyama escreveu um alentado volume intitulado O fim da história e o último homem (1992)" (ROMÃO, 2000, p. 143).

6 Em recente artigo, Leonardo Boff (2005) caracteriza bem a formação do Estado brasileiro: "Não se criou aqui uma sociedade com atores autônomos e ativos. No Brasil há um outro país feito de massa deserdadas e anônimas. O Estado, desde sua fundação, foi excludente e antipopular, apropriado por elites que o usam para garantir privilégios e realizar seus interesses. Elas não têm um projeto Brasil, incluindo a todos, mas um projeto para si, excluindo ou subordinando os demais. Só há um Estado verdadeiramente soberano e uma classe representativa quando assentados sobre uma sociedade com autores autônomos e ativos, que na verdade nunca existiu consistentemente. Sem uma sociedade organizada por cidadãos participantes, esvazia-se a democracia e se liquida a representatividade". Sobre os termos pacto social entre as elites, balcanização do Estado brasileiro ou a acumulação politizada, entende-se que "Estado e economia são vistos aqui enquanto formas da relação capitalista e, portanto, devem ser pensadas em conjunto; pensadas sob a perspectiva da necessidade, dos limites e da forma da ação estatal nos vários momentos e contextos do desenvolvimento capitalista, aí incluídas suas conformações tardias e periféricas" (FIORI, 2003 , p. 106). Por outro lado salienta-se também a limitação desses termos por induzir a uma superioridade da política em detrimento da economia, quando se compreende que "nenhuma modificação institucional fundamental ter-se-ia sustentado se não tivesse bases na estrutura produtiva [...]" (OLIVEIRA, 2003, p. 72). 
dos políticos sempre precisaram, para se manter, estar relacionados e inseridos diretamente aos interesses e ditames do Estado. Não havia poder relevante nacionalmente fora do Estado, este era o ente norteador, por excelência, da sociedade.

Sem veiculação de políticas liberais e de uma Revolução Burguesa do tipo clássico, como da Inglaterra e dos EUA, o próprio Estado Brasileiro mantinha um caráter reacionário que era escamoteado, em momentos de graves conflitos sociais ou pressões políticas, por "fugas para frente", por meio das quais se buscava alcançar crescimento econômico e geração de novos empregos, mas mantinha-se os mesmos interesses e vontades das classes dominantes anteriormente acordadas, o que impossibilitava um combate à desigualdade social. Em momentos de crises econômicas ou conflitos sociais (salientando que estas duas possuem uma relação estreita, uma vez que as crises econômicas são o momento por excelência de aparição de crises políti$\operatorname{cas}^{7}$ ), restava ao Estado brasileiro, como "fiel e honesto cumpridor de suas promessas", apenas a possibilidade de endividamento (interno e externo) para geração de investimentos na indústria e na agricultura, assegurando, assim, a repartição das verbas públicas em torno das distintas classes burguesas, a remuneração de juros para capital financeiro e investimentos ou a absorção das dívidas da burguesia industrial e oligárquica. Com a realização dessas "fugas para frente", gerou-se no Brasil um desenvolvimento visto como um tipo de "revolução passiva", sem a participação popular e sem o farol da burguesia industrial. As transformações sempre foram realizadas "por cima", procurando-se privilegiar o atendimento dos interesses das classes dominantes, sendo estas, no sentido do capital, atrasadas ou progressistas.

Com esses progressivos endividamentos do governo brasileiro, que eram derivados dos interesses do pacto social entre as classes dominantes, gerou-se, a partir dos anos 70 , uma crise econômica do Estado, que foi agravada pela de crise do capital em contexto mundial. Promoveuse, então, um descrédito com o Estado, levando a uma debandada das classes dominantes depois de colocarem em dúvida a sua capacidade de pagamento.

Por outro lado, nos anos 80 , com a emergência de distintas manifestações sociais - com destaque para as geradas pelos movimentos sindicais, produtos das industrializações tardias e da volta dos políticos e intelectuais exilados -, criou-se uma pressão em torno do Estado exigindo a abertura democrática. Como este não tinha mais liquidez nem capacidade de endividamento, não era mais possível o uso do velho recurso historicamente utilizado para aplacar crises políticas e conflitos sociais: "a fuga para frente". Assim, como saída possível restou a redemocratização.

Dois elementos marcaram, portanto, os anos 80 no Brasil: de um lado uma crise econômi$\mathrm{ca}$, e de outro um engrandecimento dos movimentos sociais, ou seja, "paradoxalmente, entretanto, durante a última década que chamamos de 'década perdida', a sociedade civil no Brasil mostrou uma extraordinária vitalidade", visto que,

[...] ao contrário do pessimismo de uma teoria política economicista, que associa queda na taxa de crescimento econômica à apatia e estados de anomia, à desorganização social enfim, a sociedade mostrou uma extraordinária capacidade de responder ao ataque neoliberal, organizando-se. Não nos esqueçamos de que nesta década foram construídas as três grandes centrais de trabalhadores, com diferenças programáticas

\footnotetext{
7 Conforme afirma Fiori (2003, p. 109), "é nas crises que mais se explicitam as contradições e se agudizam os conflitos. É também esse o momento em que as decisões vitoriosas inovam as estruturas e seu movimento cíclico de reprodução e expansão do desenvolvimento capitalista de cada sociedade concreta".
} 
e ideológicas, sem dúvida, mas num movimento totalmente contrário àquilo que o pessimismo indicava como sendo o roteiro da derrota da sociedade (OLIVEIRA, 2003, p. 25).

É desse clima de efervescência social e democrática que, tensionando o Estado, foram alcançadas conquistas trabalhistas e sociais (o que Bresser Pereira chama de burocratização), resultando na Constituição de 1988.

A partir da análise histórica, percebe-se que realmente existiu uma crise no Estado brasileiro, mas, diferentemente do que apregoa Bresser Pereira, essa crise teve como causa fundamental, no contexto mundial, a recessão advinda da crise de superprodução e de acumulação do modo de produção capitalista que serviu para agravar, no contexto nacional, o endividamento do Estado brasileiro, gerado pela imposição das regras do "pacto social" das classes dominantes que se utilizaram desta instituição da forma que Ihe foi mais conveniente ${ }^{8}$. Além disso, a constituição de 1988, longe de representar um "enrijecimento burocrático", significou um produto de lutas sociais materializadas em conquistas, ou seja, um avanço para a democracia e para qualidade de vida da população, e não um retrocesso.

\section{A SOLUÇÃO PARA A CRISE É O DESEMPREGO}

Sem levar em conta estes fatos históricos, Bresser Pereira propôs a Reforma Gerencial como forma de solucionar os problemas que afligem o Estado e a sociedade brasileira, de modo que tal Reforma surgiria como uma concepção moderna de gestão diferenciando-se de dois sistemas de pensamentos extremos: social e neoliberal, ou seja, ela se auto-proclamaria socialliberal ${ }^{9}$. Como principais objetivos para superar o quadro de crise, o autor aponta dois caminhos: um ajuste fiscal em curto prazo, e a modernização da administração pública em médio prazo. Para alcançar o ajuste fiscal, era necessário um ajuste na constituição que promovesse três mudanças:

\footnotetext{
8 Neste sentido, concorda-se com a posição de Elaine Behring de que, "em primeiro lugar, chama a atenção a explicação da crise contemporânea como crise do ou localizada no Estado. Aí estão indicadas suas causas e suas saídas, o que expressa uma visão unilateral e monocausal da crise contemporânea, metodologicamente incorreta e que empobrece o debate. Em outra perspectiva - a da crítica marxista da economia política, um patamar de observação que busca a interação de um feixe de determinações o mais amplo possível, na totalidade concreta -, tem-se que as mudanças em curso passam por uma reação do capital ao ciclo depressivo aberto no início dos anos 1970 (Mandel, 1982; Harvey, 1993), que pressiona por uma refuncionalização do Estado, a qual corresponde a transformações no mundo do trabalho e da produção, da circulação e da regulação" (BEHRING, 2003, p. 197).

9 Uma comparação entre dois textos demonstra que Bresser prefere utilizar esse termo apenas em tempos de maior aceitação ideológica da Reforma Gerencial (advinda, em grande parte graças ao papel da mídia brasileira), se caracterizando antes enquanto social-democrata. Esse é o trecho retirado do artigo de 1996: "A diferença entre uma proposta de reforma neoliberal e uma social democrática está no fato de que o objetivo da primeira é retirar o Estado da economia, enquanto que o da segunda é aumentar a governança do Estado, é dar ao Estado meios financeiros e administrativos para que ele possa intervir efetivamente sempre que o mercado não tiver condições de coordenar adequadamente a economia" (BRESSER PEREIRA, 1996, p 02). Já o seguinte trecho é retirado do artigo de 1997: "No plano econômico a diferença entre uma proposta de reforma neoliberal e uma social-democrática ou social-liberal está no fato de que o objetivo da primeira é retirar o Estado da economia, enquanto que o da segunda é aumentar a governança do Estado, é dar ao Estado meios financeiros e administrativos para que ele possa intervir efetivamente sempre que o mercado não tiver condições de estimular a capacidade competitiva das empresas nacionais e de coordenar adequadamente a economia" (BRESSER PEREIRA, 1997, p 02) (grifos nossos). Uma outra hipótese para a utilização do termo social-liberal apenas no segundo texto é que se trata de documento apresentado em congresso internacional, se distanciando um pouco dos interlocutores brasileiros.
} 
a) exoneração de funcionários por excesso de quadros; b) definição clara de teto remuneratório para os servidores; e c) através da modificação do sistema de aposentadorias, aumentando-se o tempo de serviço exigido, a idade mínima para aposentadoria, exigindo-se tempo mínimo de exercício no serviço público e tornando o valor da aposentadoria proporcional à contribuição (BRESSER PEREIRA, 1996, p. 17).

No intento de auxiliar o processo demissionário, uma forma saudável e vantajosa seria a utilização do processo de desligamento voluntário (PDV). Como defende o autor, "diante da possibilidade iminente de dispensa e das vantagens oferecidas para o desligamento voluntário, um número substancial de servidores se apresentará" (BRESSER PEREIRA, 1996, p. 17).

Para o autor, além de servir de benfeitoria para a sociedade brasileira, atendendo o "interesse público e o da cidadania", o processo de demissões de servidores públicos se caracterizaria como um benefício para os próprios funcionários, pois "todo servidor competente e trabalhador, que valoriza seu próprio trabalho, será beneficiado". Além disso, essas demissões auxiliariam na mudança da forma pela qual a sociedade brasileira enxergava os funcionários públicos, e estes conseguiriam, então, readquirir o respeito da sociedade "que foi perdido quando uma minoria de funcionários desinteressados, cujo trabalho não pode ser cobrado, estabeleceu padrões de ineficiência e mau atendimento para todo o funcionalismo" (BRESSER PEREIRA, 1996, p. 25).

De forma contrária ao que foi advogado na Reforma Gerencial, entende-se que, no intento de propiciar melhorias na qualidade do serviço público brasileiro, inclusive apontando para níveis mais elevados de eficiência (mesmo salientando que a eficiência deve ser, sempre, entendida de forma coadjuvante em relação à efetividade), deve-se investir no Estado, na qualificação e contratação de funcionários, e não em processos demissionários. Para que a população brasileira possa obter melhores graus de qualidade nos serviços públicos, faz-se necessário inserir um planejamento estratégico que vise a corrigir formas perpetuadas de clientelismo e fisiologismo. Todavia, isso não se faz com demissões, com diminuição de investimentos, com cortes de gastos sociais, e sim, de forma simetralmente oposta, com investimentos voltados para a contratação de novos quadros técnicos, com treinamentos e capacitação dos funcionários para novas formas de trabalho e de gestão, além da inserção de ferramentas e equipamentos mais avançados. A demissão de funcionários, diferentemente do que indica o discurso gerencialista, serve para agravar o quadro negativo dos serviços públicos ${ }^{10}$.

No que diz respeito ao desligamento voluntário dos funcionários públicos, apesar das supostas vantagens apregoadas, esse processo foi marcado por conturbações no espaço de trabalho, com ambientes de extrema competitividade para sobrevivência profissional, gerando vários casos de funcionários com problemas de saúde física e mental, alguns chegando a falecer e outros ficando impossibilitados ao trabalho. Além disso, a maioria daqueles que tentou iniciar

\footnotetext{
${ }^{10}$ Observa-se também que a implantação de processos demissionários se insere funcionalmente às propostas de descentralização das funções do Estado, sejam para empresas privadas, através das privatizações, seja para as organizações sociais (termo muito mais ideológico que concreto), por meio de delegação de responsabilidade e investimentos públicos, uma vez que essas práticas se tornam mais socialmente aceitáveis com a queda de qualidade nos serviços públicos. Em relação a essas esferas privilegiadas pela Reforma Gerencial, aponta-se para uma mistura dos pensamentos da dita moderna intelligentsia: práticas neoliberais de privatização, potencializadas pela descentralização para ONGs, advogada pela suposta Terceira Via. Sobre esse aspectos, formulam-se críticas posteriormente, aqui cabe apenas a seguinte reflexão: é possível estabelecer limites e fronteiras entre essas duas ideologias. Onde começa uma e termina outra?
} 
um trabalho próprio não conseguiu obter sucesso nos empreendimentos investidos com os recursos de toda a vida de trabalho, devido à falta de preparo técnico, mas, principalmente, pela elevada monopolização do mercado, levando, da mesma forma, a novos casos de problemas físicos e mentais.

Sobre a implementação dessas novas políticas que visavam supostamente a erradicar a burocracia do serviço público brasileiro, verificou-se que essas resultaram na geração de espaços internos de competitividade entre os funcionários, o que serviu em última instância para minar a própria força da classe trabalhadora, uma vez que foram colocados uns contra outros na busca pela manutenção do emprego. Da mesma forma, a reverberação ideológica e ideologizante da existência desses "marajás" ${ }^{11}$ que empestaram o Estado brasileiro e que só seriam erradicados com a implantação da lógica eficiente de mercado, dando o tom dessas propostas, serviu para colocar a sociedade contra os funcionários públicos e, pior, em último caso, fomentou as bases ideológicas para um crítica mútua entre os trabalhadores, de acordo com categorias particulares.

Os próprios trabalhadores da iniciativa privada colocaram-se em posição crítica aos seus semelhantes dos serviços públicos, uma vez que, por aproximarem-se do novo discurso em pauta, se situaram de forma contrária à garantia de estabilidade, enxergando-a como mordomia. O caso mais famoso desse erro infantil da assimilação da ideologia neoliberal pelos trabalhadores se deu na reforma da previdência, a partir da qual algumas categorias trabalhistas defendiam a destruição de conquistas sociais resultantes de lutas históricas da classe trabalhadora.

A mídia brasileira também assimilou as propostas gerencialistas fortalecendo a ofensiva contra a organização da classe trabalhadora. Além de veicular distintas reportagens sobre as supostas mordomias dos funcionários públicos, essas instituições promoveram guerras particulares entre as categorias trabalhistas, principalmente em momentos de greves nos quais, além de tentar colocar a sociedade contra os trabalhadores (nas entrevistas televisivas que mostram pessoas reclamando dos problemas sociais acarretados pelas greves), também tentaram colocar as categorias trabalhistas umas contra as outras (um exemplo corrente a ser destacado é o da greve de funcionários de universidades, quando se realizam entrevistas com professores insatisfeitos, indignados com essa paralisação, pois prejudica seu trabalho e a toda a população).

\section{PRIVATIZAÇÃO, PUBLICIZAÇÃo E O PÚBLICO-NÃO-ESTATAL}

Para alcançar a modernização da administração pública, na Reforma Gerencial apresentava-se um projeto que atenderia a dois objetivos: fortalecer o núcleo estratégico, ou a administração pública direta, e descentralizar os serviços que não fossem dessa esfera, a partir de descentralização de responsabilidades e recursos para organizações sociais e agências executivas. Diante da crise fiscal do Estado que "retirou-lhe capacidade de realizar poupança forçada e investir nas empresas estatais", e na esteira do discurso de modernização do Estado brasileiro e da administração pública, introduzia-se a legitimação dos processos de privatizações de entidades estatais para gerar um contexto de maior eficiência. Para a disseminação dessa proposta afirmava-se que, estando nas mãos do mercado, as organizações estatais que antes produziam serviços de baixa qualidade por serem burocráticas e clientelistas/fisiológicas, passariam por um processo natural de modernização, tornando-se mais eficientes, visto que não se questiona-

\footnotetext{
${ }^{11}$ Termo que ficou famoso nos discursos de Fernando Collor e que foi incorporado e legitimado por Bresser Pereira (1997, p. 14): "estas incorporações de vantagens temporárias e as acumulações de cargos, habilmente manipuladas, permitiram que um número crescente de servidores passassem a ganhar altos salários, surgindo então a expressão 'marajás' para identificar esses funcionários".
} 
va a ideia de que "as empresas serão mais eficientes se controladas pelo mercado e administradas privadamente". Neste sentido, o Estado brasileiro deveria ter como papel central o de "regulador e transferidor de recursos, que garante o financiamento a fundo perdido das atividades que o mercado não tem condições de realizar" (BRESSER PEREIRA, 1996, p. 20), em concordância com uma "concepção de que o Estado moderno que prevalecerá no século XXI" não seria nem o liberal, tampouco o executor.

Diante desse novo quadro, o papel desse Estado moderno deveria, portanto, restringirse, sendo preciso, para este fim, um amplo processo de descentralização, tendo por base três formas distintas de propriedade: a estatal e pública, a privada, e a pública não-estatal. Inicialmente, promover-se-ia "a descentralização dos serviços sociais do Estado, de um lado para os Estados e Municípios", depois, "do aparelho do Estado propriamente dito para o setor público não-estatal", formado por empresas privadas com fins lucrativos e sem fins lucrativos, as chamadas públicas não estatais. Para aquele tipo de empresas, a privatização; para este tipo, a publicização. Bresser Pereira (1996, p. 23), chamava a atenção para esse último elemento, fazendo questão de ressaltar que se tratava de um processo que não poderia ser confundido com as privatizações $^{12}$, pois, nas suas palavras,

[...] a transformação dos serviços não-exclusivos de Estado em propriedade pública não-estatal e sua declaração como organização social se fará através de um "programa de publicização", que não deve ser confundido com o programa de privatização, na medida que as novas entidades conservarão seu caráter público e seu financiamento pelo Estado. O processo de publicização deverá assegurar o caráter público mas de direito privado da nova entidade, assegurando-Ihes, assim, uma autonomia administrativa e financeira maior.

Para Bresser Pereira, existiam, portanto, duas formas de transferência das atividades do Estado brasileiro para instituições não estatais: a privatização, na qual os setores não estratégicos do Estado seriam comercializados para a iniciativa privada, e a publicização, na qual setores de maior importância social seriam cedidos a organizações sociais, ou não governamentais. $\mathrm{Na}$ sua perspectiva, a transferência de atividades públicas para as Organizações não Governamentais - ONGs, além de implicar melhoria na qualidade do serviço - pois se passaria a ter uma gestão mais eficiente, conseguindo-se afastar práticas clientelistas -, a formação desses supostos novos espaços públicos não estatais acarretaria num aumento da democracia. Conforme afirma o autor, se a "privatização é uma alternativa adequada quando a instituição pode gerar todas as suas receitas da venda de seus produtos e serviços, e o mercado tem condições de assumir a coordenação de suas atividades", nos momentos em que isso não ocorre, devido à crise na relação entre Estado e empresas privada, "o espaço público não-estatal pode ter um papel de intermediação ou pode facilitar o aparecimento de formas de controle social direto e de parceria, que abrem novas perspectivas para a democracia" (BRESSER PEREIRA, 1996, p. 22).

Utilizando-se de uma perspectiva de exacerbação das negatividades do Estado, de que, "a inépcia estatal seria uma característica congênita, bem como sua vocação excludente, dada

\footnotetext{
12 Já aqui duas reflexões merecem destaque, visto que, se ele fez tanta questão para salientar a diferença entre as duas propostas, observa-se que: ou a privatização era vista até por ele mesmo como um processo negativo ou a publicização teria elementos que a assemelhavam as privatizações, e por isso deveria se atentar para suas diferenças.
} 
que a burocracia estaria sempre voltada a extrair benefícios para si própria, mais que promover a democratização do acesso aos recursos e serviços que controla" (COSTA, 2001, p. 26), no que diz respeito ao atendimento social, que foi agravado pela crise do Estado, advoga-se que somente será possível uma democratização dos serviços públicos através da delegação de responsabilidades do Estado para organizações privadas, independentes, que estejam mais próximas da população. Estabeleceu-se, pois, um lastro material que incidiu diretamente no debate sobre as arestas entre o público e o privado.

Como o Estado seria, por natureza, configurado por práticas burocráticas e clientelistas, a solução para prover atendimento público para a população seria o incentivo à criação de organizações não governamentais (ONGs) de natureza privada, mas com finalidade pública. Todavia, para tal empreitada se fez necessária a própria criação de uma nova categoria jurídica para legitimar a existência dessas novas organizações, uma vez que seria uma inovação na forma de compreender as dimensões sociais. Agora, com o advento desses novos empreendimentos, não estariam mais separadas a instância privada e o espaço público, visto que estes seriam vinculados, formando uma organização de natureza privada e finalidade pública. Nesse sentido, Bresser Pereira (1996, p. 20) se coloca como um inovador no sentido de entender a relação entre público e privado:

[...] no capitalismo contemporâneo as formas de propriedade relevantes não são apenas duas, como geralmente se pensa, e como a divisão clássica do Direito entre Direito Público e Privado sugere - a propriedade privada e a pública -, mas são três: (1) a propriedade privada, voltada para a realização de lucro (empresas) ou de consumo privado (famílias); (2) a propriedade pública estatal; e (3) a propriedade pública não-estatal, que também pode ser chamada de não-governamental, não voltada para o lucro, ou propriedade do terceiro setor.

Inicialmente, como primeiro ponto de crítica, vale salientar que não se trata realmente de uma inovação, mas de uma tendência gerada pelo neoliberalismo, no qual se induz a fazer com que o poder encontre-se "fora do espaço público", visto que "as instituições políticas tradicionais" estariam "progressivamente incapacitadas de fornecer qualquer tipo de segurança ou garantia a seus cidadãos". A consequência ideologia central desse processo foi a difusão da ideia de "privatização dos meios" como "ilusão de assegurar a liberdade individual", o que levou "à crescente polarização social e a um ambiente de medo difuso e insegurança geral que não favorece a articulação de uma ação coletiva" (DUPAS, 2003, p. 20-21).

Sobre essas propostas de descentralização como forma de modernização do serviço público, há uma relação entre dois objetivos que são excludentes, mas que aparecem na Reforma Gerencial como complementares. Conforme consta anteriormente, Bresser Pereira defende que, para modernizar a administração pública brasileira, deve-se seguir dois caminhos: fortalecer a administração pública e descentralizar responsabilidades para outros tipos de organizações da sociedade. Observa-se que existe, entre esses dois objetivos, uma mútua exclusão, uma vez que, lembrando algumas críticas anteriores, para se fortalecer a administração pública se fazem necessários investimentos na capacitação e qualificação dos quadros, além de inserção de novas tecnologias e a não delegação das atividades do Estado para outras agências privadas ou pseudopúblicas que, pela própria definição ideológica, possuem interesses distintos do Estado.

A ideia da passagem para a auto-responsabilização de municípios ou estados, por meio de processos de descentralização das funções do governo - antes federalizadas -, serviria para combater o aparelhamento privado do bem público, pois se extinguiria a corrupção instalada. 
Quando testada empiricamente, porém, tal passagem contraria o advogado, visto que, de acordo com pesquisa realizada pela CEPAL em 1998, na prática, "a descentralização foi considerada como importante fonte de corrupção e de perda de controle fiscal", além de "ter contribuído para ampliar as brechas inter-territoriais dos indicadores educativos e de saúde" (SOARES, 2002, p. 78).

Além disso, como a forma de descentralização em voga na perspectiva gerencialista é concebida como uma mera transferência de responsabilidade do ente federativo para as instâncias inferiores, com a falta de financiamento para os níveis estadual e local agrava-se o quadro de degradação dos serviços públicos. Assim, de forma contrária às propostas defendidas por Bresser Pereira, percebe-se que, de acordo com as evidências, "a garantia de um desenvolvimento regional e local eqüitativo passa por uma atuação decisiva dos governos federal e estaduais", ou seja, é somente a partir de uma atuação articulada entre as instâncias do Estado que é possível fortalecer a atuação das prefeituras municipais (SOARES, s/d, p. 11).

No que diz respeito às práticas de privatização, apesar de já existirem muitas críticas sobre o assunto ${ }^{13}$, valeria salientar aqui que, além das transferências de recursos financeiros para organizações sociais públicas não estatais (de acordo com a perspectiva gerencialista), poder-se-ia incluir tecnicamente o que aconteceu na prática: uma própria transferência de recursos para as empresas privadas a partir das privatizações, nas quais vários benefícios foram disponibilizados, desde financiamento público até responsabilização de dívidas e encargos sociais por parte do Estado, assim como garantias de consideráveis margens de lucros futuros. Além de ceder as organizações estatais para o mercado, tudo isso amarrou o governo a ainda garantir lucratividade, o que ocasiona, inclusive, a negação de uma das premissas tão caras ao capitalismo, que é o livre comércio.

Além desses fatos que contradizem a proposta, outra característica se tornou visível depois desse processo de privatizações, também servindo para desmistificar a Reforma Gerencial: a maioria dos serviços que antes eram realizados pelo Estado ${ }^{14}$, inclusive tidos como estratégicos para o desenvolvimento nacional e para a sociedade, ao passarem para a iniciativa privada, tiveram um significativo aumento no preço, inclusive, com quedas na qualidade prestada.

A partir das práticas de privatização, instaurou-se uma dualidade nos serviços, uma vez que, de um lado os serviços públicos tiveram uma queda na qualidade, enquanto de outro lado, os serviços melhores tiveram um significativo aumento de preço. Por isso, pode-se afirmar que "a principal conseqüência da privatização tem sido, na realidade, a introdução de uma dualidade discriminatória: serviços melhores para quem pode pagar (privados), e de pior qualidade ou nulos para quem demanda o acesso 'gratuito'"' (SOARES, 2002, p. 78).

\footnotetext{
${ }^{13}$ Os textos de maior destaque ainda são as obras de Aluísio Biondi (1999; 2000).

${ }^{14}$ É importante não cair na falácia de que, com a delegação de responsabilidades, se trata de um Estado Mínimo, uma vez que, conforme explicita Soares (s/d, p. 02), "a reforma do Estado não se limita a uma redução do tamanho do Estado (aquilo que ficou cunhado nas teses neoliberais como 'Estado Mínimo'). Trata-se de retirar o Estado de algumas áreas reforçando-o em outras. Para que as medidas de ajuste e as reformas sejam implementadas é preciso que o próprio Estado se fortaleça em termos de recursos financeiros e de poder, já que é ele, em última instância, o principal agente da sua própria reforma. O Estado é absolutamente necessário para desregulamentar a economia, flexibilizar as relações de trabalho; e patrocinar as reformas consideradas "indispensáveis" para o êxito do modelo neoliberal. Tal 'patrocínio' passa, inclusive, pela cooptação e compra do Legislativo por parte do Executivo, garantindo a fachada 'democrática' das reformas". Ou ainda, "para que as medidas de ajuste e as reformas sejam implementadas é preciso que o próprio Estado garanta recursos financeiros e poder aos novos setores 'estratégicos' para o capitalismo, como o setor financeiro. O Estado é absolutamente necessário para desregulamentar a economia e flexibilizar as relações de trabalho" (idem, p. 08).
} 
Uma análise crítica do último ponto, referente à proposta de transferência de recursos e responsabilidades do Estado para organizações públicas não estatais (de natureza privada com finalidade pública), definida pelo conceito de publicização, demonstra que, além desse processo ter repercutido na precarização de trabalho - expresso desde o nível inferior na remuneração proposta, a baixa carga horária, até o gradativo aumento de trabalho efetivo ${ }^{15}$-, ele teve por principal resultado uma tendência retroativa de democracia, forjada pela negação ideológica e material dos direitos sociais.

Como se observou, as supostas empresas privadas com fins públicos surgem, para Bresser Pereira, como a esfera necessária para gerar serviços àquelas pessoas sem condições de pagar pelos mesmos, por isso seria o outro lado da moeda, na qual estaria a privatização. Todavia, entende-se que desse modo se nega tanto a universalidade dos serviços quanto a existência de direitos sociais, uma vez que apenas aquelas pessoas que não tiverem condições financeiras para pagar por um serviço privado serão beneficiadas pelas organizações sociais. Focalizam-se os serviços públicos nas pessoas mais miseráveis (por isso, em alguns casos chega-se a requerer o "atestado de pobreza" para propiciar atendimento), rompendo com o aspecto universalizante, e entendem-se se serviços públicos enquanto um benefício doado ${ }^{16}$.

Considerando-se o serviço público como um benefício, consequentemente, nega-se sua permanência, tornando-o, desta forma, um não-direito. A proposta de publicização aparece como um encaixe necessário para manter uma política (material e ideológica) de negação dos direitos sociais, uma vez que, a partir do momento em que se estabelece a naturalização da publicização, gera-se uma negação da materialidade dos direitos sociais, agravada pela negação da consciência sobre as políticas sociais como um direito. A publicização, ao negar os direitos sociais, situando-os como benefícios das organizações sociais - que decidem de forma particular o destino da população (em termos técnicos da Reforma Gerencial, a tão louvada autonomia das organizações socais) -, situa-se, portanto, na contramão do controle da corrupção, assim como inviabiliza espaços mais democráticos.

A partir do momento em que se estabelecem novas formas de distanciamento entre a origem do serviço público e a pessoa que vai recebê-lo, seja através da entrada em cena de instituição estatais locais ou não estatais, introduzem-se intermediários neste processo, acarretando o contrário do falaceado: no lugar de combater o clientelismo e o fisiologismo, criam-se novas possibilidades concretas para que estas práticas sejam ampliadas. Se o serviço vem direto do Estado para a população, não havendo desresponsabilização da União, existe um contato direto entre as duas esferas, entre os dois extremos do serviço público. Quando entram novas instituições em jogo, fortalecem-se as elites locais que historicamente se utilizaram dos serviços públicos e gratuitos para fins particulares, sejam eleitoreiros ou para enriquecimento direto.

Além disso, atrelando-se esse processo com uma ideologia de "fim da história", de naturalidade da desigualdade social e de problemas sociais, cria-se nas pessoas uma perspectiva de

\footnotetext{
${ }^{15}$ Conforme demonstra Montaño (2002, p. 254), baseado em Serra (1998): "nas entidades filantrópicas, e especialmente nas ONGs (estas em mais de 40\%), há forte presença de contratos terceirizados de assistentes sociais [...]"; "por outro lado, no Rio de Janeiro, os assistentes sociais das entidades filantrópicas recebem, quase na sua totalidade, salários equivalentes às duas faixas mais baixas [...]"; "A pesquisa também mostra a baixa carga horária dos assistentes sociais nas entidades filantrópicas (mais de $50 \%$ com $20 \mathrm{~h} /$ semanais) e nas ONGs (20\% com 20 e $20 \%$ com 25 h/semanais) [...]".

${ }^{16}$ Inclusive as próprias organizações sociais passaram a repetir essa lógica, uma vez que, além de escamotear o financiamento público, colocando o Estado como um ente desnecessário e negativo no atendimento social, seus integrantes se postam como sendo os mais credenciados heróis a serviço da humanidade, os únicos capazes de sanar os problemas sociais e que fazem aquilo por boa vontade. Por isso, o atendido não pode abusar desse favor e chegar ao cúmulo de analisar como o serviço público um direito de cidadania.
} 
individualidade, não só para sobrevivência própria, como para ajuda aos semelhantes. A união dessa visão de mundo com a perspectiva individualista e individualizante tem algumas consequências que merecem destaque pela importância na reprodução e ampliação da reificação: a pessoa escolhe quem deve ajudar, a partir de critérios seletivos para decidir entre os mais pobres, ou por aquele segmento por quem tem mais proximidade ou simpatia. Como não pode ajudar a todos, escolhe um grupo mais representativo individualmente. Sendo a ajuda representada como uma superação da busca incessante pela sobrevivência individual, estando todos, dentro do contexto atual de desemprego, voltados para angariar recursos para manutenção da sua própria vida e de sua família, aqueles que não se limitam a isso, que se dedicam a esse tipo de solidariedade em pauta, tendem a transformar esse sentimento numa adjetivação para sua própria autopromoção, muitas vezes se colocando como um exemplo a ser seguido.

Neste sentido, criam-se supostos heróis, que se utilizam de qualidade pseudo-sociais como símbolos de status, gerando-se uma quase competição pelos graus de heroísmo, o que leva a um distanciamento gradativo da classe, dos coletivos e do Estado, mas sendo aproveitado e propagado pelo mercado. $O$ mercado, por sua vez, como é a esfera que mais estimula esse tipo de prática (se não de forma direta, através de supostas doações), passa a ser a central ou até única capaz de arregimentar forças para promover os atos solidários. Entretanto, não se percebe que, se essa prática é perpetuada e incentivada, isso se deve à razão de que é o mercado o principal beneficiário dessa forma de intervenção social (que é contrária à sociedade), sendo, ao mesmo tempo, origem e resultado dessas atitudes e de suas consequências.

Com esses recursos, fratura-se o espaço público inclusive da sua especificidade da esfera subjetiva, pois transforma sua capacidade de atendimento e ouvidoria universal da política pública em assistência particular. Surge, portanto, uma nova determinação no debate entre público e privado oriundo desde os primeiros analistas políticos (como Platão ou Aristóteles), que instala um abismo entre essas duas esferas sociais. Esse problema apresenta-se diretamente na organização dos atores coletivos.

Na prática, com o desvirtuamento dos problemas sociais de sua causa central - a contradição entre capital e trabalho, ilustrando o mercado não como um espaço de conflito entre classes, mas como a esfera de ajuda social, e situando o Estado como incapaz de efetivar sua responsabilidade de atendimento público e

[...] a partir da 'naturalização' das desigualdades, o modelo devolve o conflito para o seio de uma sociedade fragmentada, onde os 'atores' se individualizam, ao mesmo tempo que os sujeitos coletivos perdem identidade. Muda, portanto, a orientação da política social: nem consumos coletivos, nem direitos sociais, senão que assistência focalizada para aqueles com 'menor capacidade de pressão' ou os mais 'humildes' ou, ainda, os mais 'pobres'. Dessa forma, o Estado Neoliberal ou de 'MalEstar' inclui, por definição, uma feição assistencialista (legitimação) como contra-partida de um mercado 'livre'(acumulação). Essa política de legitimação tem oscilado, particularmente nos países da América Latina, entre o assistencialismo e a repressão (SOARES, 2002, p. 73).

Com isso ocorre uma desfiguração do conceito de solidariedade, para que este se torne funcional à ordem estabelecida. Uma solidariedade sem compromisso de classe nem questionamento social, mas que seja individualista, limitando a causa e a solução dos problemas nas próprias pessoas que são atingidas, o que leva à transformação de vítimas em réus. 
Essa questão está intimamente relacionada com a própria forma de se compreender as características do que venha a ser cidadania e democracia. Sendo estes dois elementos tendenciados por esta perspectiva individualista e individualizante, passam a ter uma desvinculação com a totalidade social, com a sociedade vista a partir de suas inter-relações e múltiplas determinações, compreendendo o indivíduo de forma isolada, tal qual ilustra a definição propagada pelo pensamento liberal sobre a sociedade, como sendo composta de um mero agrupamento de indivíduos, cada um com seus interesses e problemas isolados. E assim, ao negligenciar uma perspectiva coletiva, o ser humano passa a ser posto e sentido como isolado e único responsável pelos seus problemas. Desta maneira, qualquer forma de ajuda aos outros, ou qualquer expressão de sentimentos de solidariedade será tido como de boa vontade ${ }^{17}$, como um favor disponibilizado, e não como um serviço necessário para a própria manutenção do ordenamento social.

É por isso que ocorre um agravamento da alienação política e social: se antes a solidariedade pressupunha um direito social a ser prestado pelas instituições do Estado, mas que não era analisado de forma crítica, expondo suas inerências à manutenção da ordem (o questionamento da relação entre as políticas sociais e a legitimidade da legalidade capitalista), agora nem sequer o próprio direito social é visto como tal, e sim como um favor a ser disponibilizado por outras pessoas, negando a importância das instâncias do Estado. Se a solidariedade era transmutada em solidariedade capitalista, pelo menos expressava elementos que influíam na consciência em relação aos direitos sociais (mesmo escamoteando que a similitude entre democracia e igualdade, dentro do contexto capitalista, é uma abstração). Já nos tempos mais recentes, a partir do capitalismo neoliberal, agrava-se o processo de des-concientização política, condicionando a definição de solidariedade a um patamar regressivo que nega sua vinculação com a sociedade e o Estado e que legitima-se como ideologia neoliberal.

Conduz-se a humanidade para

[...] um sistema onde cada um é solidário, desde que a isso se disponha, com seus pares, com seus iguais ou semelhantes, com seu grupo de interesse particular. A substituição do princípio de solidariedade baseada em direitos universais (presente no sistema de tributação direta, na previdência única, na seguridade e nas políticas sociais do Welfare State) faz com que cada grupo ou coletivo que apresenta uma necessidade ou carência particular tenha que se auto-responsabilizar (direta ou indiretamente) pelo financiamento/prestação da sua resposta; e este é o grande desejo/finalidade do projeto neoliberal (MONTAÑO, 2002, p. 167).

De forma adversa a essa proposta neoliberal, entende-se que, para se estimular uma participação política dos agentes sociais, ingrediente central para o fortalecimento da democracia, deve-se manter uma relação entre iguais. 0 posicionamento dos atores coletivos deve ser

\footnotetext{
${ }^{17}$ Segundo a vertente do terceiro setor, estando o Estado falido, uma das poucas saídas possíveis para amenizar os problemas sociais é através da mudança por valores: "Na verdade, no lugar deste termo, o fenômeno real deve ser interpretado como ações que expressam funções a partir de valores. Ou seja, as ações desenvolvidas por organizações da sociedade civil, que assumem as funções de resposta às demandas sociais (antes de responsabilidade fundamental do Estado), a partir dos valores de solidariedade local, auto-ajuda e ajuda mútua (substituindo os valores de solidariedade sociais e universalidade e direitos dos serviços)" (MONTAÑO, 2002, p. 184).
} 
de inserir-se na luta para defender os direitos da população e, em especial, daqueles que sentem mais diretamente as contradições do modo de produção capitalista. É justamente o contrário do proposto e praticado por instituições do chamado "Terceiro Setor" que, naturalizando os problemas sociais, também se postam como organizações 'supraclassistas', com o papel único de prover auxílios, em forma de atividades voluntárias e voluntariosas que, em si, já representam uma negação do caráter de direito social, disseminando a lógica do favor, da doação e da despolitização.

Se os problemas são irremediáveis e, pior, não podem ser compreendidos como tendo responsáveis ou causadores, qualquer posicionamento de crítica ao sistema capitalista constitui uma loucura e, por outro lado, a única saída que resta é a harmonização social e a disponibilização de práticas de boa vontade. Transforma-se um movimento de perspectiva política - que possibilita a vigência de uma consciência crítica voltada para a exigência de direitos sociais e políticas públicas - numa perspectiva conciliadora e reprodutora da ordem social estabelecida, tendendo-se irremediavelmente para o aprofundamento das contradições sociais.

\section{A QUEM SE DESTINA A CRIATURA}

Finalmente, mesmo com as várias dificuldades enfrentadas para a aceitação da Reforma Gerencial, Bresser Pereira (1996, p. 31) se coloca em uma posição otimista, pois acredita que existem motivos que levam a pensar no seu sucesso. Nas palavras do autor, "apesar das dificuldades que a reforma vêm enfrentando, seja no Congresso, seja na sua efetiva implementação na administração, existem boas razões para pensarmos em perspectivas otimistas". Para ele, depois de um período de desconfiança, sua proposta estava começando a ser compreendida e aceita de diversas maneiras pela sociedade. Como forma de demonstrar esse apoio recebido, ele cita que "uma enquete feita recentemente entre as elites brasileiras apontou um forte apoio à reforma, particularmente entre os empresários e os altos administradores públicos".

A explicitação da base de apoio que é citada por Bresser Pereira para aprovar a Reforma não parece ser casual, mas, pelo contrário, aponta para a classe das pessoas que se convenceram mais depressa dos efeitos positivos da sua proposta: como ele mesmo indica, as elites brasileiras. No final das suas argumentações, parece que ele aponta para aqueles que merecem mais atenção pelo seu trabalho e que devem ser mais favorecidos. Neste sentido, propor uma forma de ver o Estado que não seja apropriado privadamente é, no mínimo, uma contradição. Pelo menos devia colocar uma ressalva: proibido o aparelhamento privado do Estado brasileiro, pelas classes desfavorecidas. Para estas é necessário ter um Estado eficiente que não se exagere no gastos sociais e que não estimule a adoração de conquistas sociais, como parece ser para ele a constituição de 1988.

Não se trata, entretanto, de mera provocação, mas explicita-se que essa é a forma histórica correntemente utilizada pelas elites brasileiras para fazer uso da política no país: enriquecimento ilícito por meio de apropriação privada do bem público, disfarçada algumas vezes por ameaças de ditadura militar e, outras vezes, por ingredientes de cinismo e mistificação. Ou seja, essa é "a forma como a grande burguesia faz política entre nós: quando não joga no golpe, quando joga na legitimação política por via eleitoral, fá-lo através da mistificação e do cinismo" (NETTO, 1995, p. 34).

No final, percebe-se que a suposta proposta modernizante da Reforma Gerencial, com sua inovadora visão sobre o espaço público, democraticamente retratada pela inserção das organizações públicas-não-estatais, representa não um avanço social contras os problemas que afligem o povo brasileiro, e sim se constitui enquanto uma nova ferramenta de exclusão social a 
serviço do capital. Com isso, observa-se que as reformas implementadas "não eram para ampliar e democratizar o Estado, mas para 'enxugar' e 'modernizar' a 'máquina estatal'", isso é, "flexibilização dos direitos e terceirização dos contratos". Reformas que, no lugar de servir para prover recursos que fossem destinados à população, além de instaurar novos canais de participação democrática, "mantiveram o livre trânsito dos interesses dominantes no interior do Estado, permitindo a rapinagem dos recursos públicos (em escala nunca antes vista) derivada da 'privataria', onde a corrupção nunca foi investigada" (SOARES, 2005, p. 7).

\section{REFERENCIAS BIBLIOGRAFICAS}

ANDERSON, Perry. Balanço do neoliberalismo. In. SADER, Emir; GENTILI, Pablo (orgs). Pós-neoliberalismo: as políticas sociais e o estado democrático. 6. ed. Rio de Janeiro: Paz e Terra, 2003.

BEHRING, Elaine Rosseti. Brasil em contra-reforma: desestruturação do Estado e perda de direitos. São Paulo: Cortez, 2003.

BORÓN, Atílio. A sociedade civil depois do dilúvio neoliberal. In. SADER, Emir; GENTILI, Pablo (org). Pósneoliberalismo: as políticas sociais e o estado democrático. 6. ed. Rio de Janeiro: Paz e Terra, 2003.

BIONDI, Aloysio. O Brasil privatizado II: o assalto das privatizações continua. São Paulo: Fundação Perseu Abramo, 2000. 1999.

O Brasil privatizado: um balanço do desmonte do Estado. São Paulo: Fundação Perseu Abramo,

BOFF, Leonardo. Salvar o capital de esperança. In: Jornal do Brasil, 01 de julho de 2005.

BRESSER PEREIRA, Luiz Carlos. Um novo aprendizado. In: Folha de São Paulo, 10 de janeiro de 1999.

. O neoliberal disfarçado ou os percalços de uma certa lógica. In: Lua Nova - Revista de Cultura e Política, n. 46. São Paulo: CEDEC, 1999.

. Uma reforma gerencial da administração pública no Brasil. In: Anais do Congresso da Associação Internacional de Ciência Política - IPSA. Seul, agosto de 1997. 1996.

Da administração pública burocrática à gerencial. In: Revista do Serviço Público, n. 47 (1), janeiro de

COSTA, Márcio da. A educação em tempos de conservadorismo. In.GENTILI, Pablo (org.). Pedagogia da exclusão: crítica ao neoliberalismo em educação. 9. ed. Petrópolis: Vozes, 2001.

DUPAS, Gilberto. Tensões contemporâneas entre o público e o privado. São Paulo: Paz e Terra, 2003.

FIORI, José Luís. O vôo da coruja: para reler o desenvolvimento brasileiro. Rio de Janeiro/São Paulo: Record, 2003.

LANDER, Edgardo. Conhecimento para quê? Conhecimento para quem? Reflexões acerca da geopolítica dos saberes hegemônicos. In: GENTILI, Pablo (org.). Universidades na penumbra: neoliberalismo e reestruturação universitária. São Paulo: Cortez, 2001. 
Neoliberalismo, reforma do estado e o público-não-estatal: novos contornos entre o público e o privado.

LEHER, Roberto. Projetos e modelos de autonomia e privatização das universidades públicas. In: GENTILI, Pablo (org.). Universidades na penumbra: neoliberalismo e reestruturação universitária. São Paulo: Cortez, 2001.

MANDEL, Ernest. O capitalismo tardio. São Paulo: Abril Cultural, 1982. (col. Os economistas)

MONTAÑO, Carlos. Terceiro setor e questão social: crítica ao padrão emergente de intervenção social. São Paulo: Cortez, 2002.

NETTO, José Paulo. Crise do socialismo e ofensiva neoliberal. São Paulo: Cortez, 1993.

OLIVEIRA, Francisco de. Neoliberalismo à brasileira. In: SADER, Emir; GENTILI, Pablo. Pós-neoliberalismo: as políticas sociais e o Estado democrático. 6. ed. São Paulo: Paz e Terra, 2003.

A economia brasileira: crítica à razão dualista. In: OLIVEIRA, Francisco de. Crítica a razão dualista, o ornitorrinco. São Paulo: Boitempo Editorial, 2003.

ROMÃO, José Eustáquio. Dialética da diferença - o projeto da escola cidadã frente ao projeto pedagógico neoliberal. São Paulo: Cortez, 2000.

SOARES, Laura Tavares. O desastre social. Rio de Janeiro: Record, 2003.

. Os custos sociais do ajuste neoliberal na América Latina. 2. ed. São Paulo: Cortez, 2002.

. Globalização e o papel do Estado na proteção da vida. Rio de Janeiro, s/d, mimeo.

THERBORN, Goran. A crise e o futuro do capitalismo. In: SADER, Emir; GENTILI, Pablo (org). Pós-neoliberalismo: as políticas sociais e o estado democrático. 6. ed. Rio de Janeiro: Paz e Terra, 2003. 